\section{DIGITAL COMMONS \\ @ UNIVERSITY OF SOUTH FLORIDA}

\section{Revista Surco Sur}

\title{
Estudios Transatlánticos: en torno a un proyecto académico Interuniversitario
}

Juan Antonio García Galindo

\section{Recommended Citation}

García Galindo, Juan Antonio. 2014. Estudios Transatlánticos: en torno a un proyecto académico Interuniversitario. Revista Surco Sur, Vol. 4: Iss. 6, 61-64.

DOI: http://dx.doi.org/10.5038/2157-5231.4.6.14

Available at: https://digitalcommons.usf.edu/surcosur/vol4/iss6/15

This PUNTO FINAL is brought to you for free and open access by the Open Access Journals at Digital Commons @ University of South Florida. It has been accepted for inclusion in Revista Surco Sur by an authorized editor of Digital Commons@ University of South Florida. For more information, please contact digitalcommons@usf.edu. 


\section{Juan Antonio García Galindo}

\section{Estudios}

\section{Transatlánticos: en torno a un proyecto académico}

\section{Interuniversitario}

Este ensayo breve responde a un proyecto académico interuniversitario, que intenta plantear las bases para un futuro programa coordinado de Estudios Transatlánticos entre la Universidad del Sur de la Florida y la Universidad de Málaga. No deja de ser una arriesgada incursión en un ámbito nuevo del

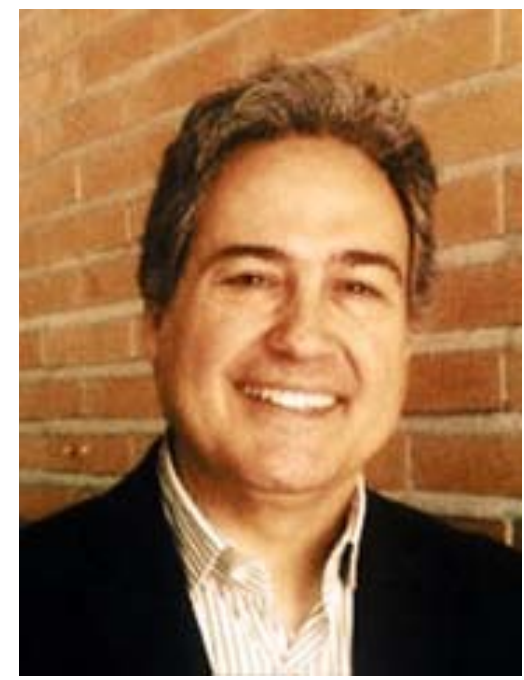
conocimiento, explorado sobre todo desde los estudios culturales y desde los estudios latinoamericanos, especialmente literarios, que tiene apenas dos décadas de existencia. Y no tiene más pretensión que mostrar nuestra inquietud académica e intelectual en torno a la idea de establecer un marco académico y científico que permita a las dos universidades colaboradoras en el proyecto avanzar en la construcción de un programa formativo multidisciplinar que tenga como referencia al Mundo Atlántico como espacio dialógico y de intercambios sociales, culturales, políticos y económicos. Dicha multidisciplinariedad debería ser la base para un futuro trabajo interdisciplinar y transdisciplinar, más cercano a los problemas del mundo real aunque no ajeno al debate propiamente científico. Puede adolecer, sin embargo, nuestra propuesta de tener un carácter generalista frente a otros enfoques más especializados, pero consideramos que en el actual estado de la cuestión falta una visión panorámica, pero no menos específica, que permita entender la cantidad y variedad de los flujos que se producen entre las dos orillas, sobre todo en el espacio Europa-EEUU-América Latina. Pensamos que la mejor manera de entender los procesos de interacción y de diálogo que se producen en esos territorios es, partiendo siempre de los estudios especializados, mostrar la estructura latente que se halla detrás de ellos en todos los planos de la realidad histórica.

\section{La complejidad del espacio académico}

La tradición universitaria de los Estudios Transatlánticos es importante en el ámbito de la literatura y de los estudios culturales, donde se han producido grandes avances, centrados sobre todo en los cruces culturales y en los procesos de mestizaje que se han dado en ambas orillas del Atlántico, y en El Caribe como espacio con naturaleza propia, que puede integrarse, no obstante, en el campo más amplio de los Estudios Transatlánticos. Sin renunciar, obviamente, a esa tradición científica, por otro lado de gran repercusión académica y fundamental para comprender el desarrollo multidisciplinar que proponen los nuevos enfoques. La interdisciplinariedad habrá de ser uno de nuestros objetivos. Así pues, aunque su desarrollo haya sido mayor desde los estudios literarios comparados, la perspectiva que defendemos responde al binomio multidisciplinar/ interdisciplinar.

Es cierto que en los últimos años se ha desarrollado también una tendencia de estudios transatlánticos hispánicos que algunos autores atribuyen al interés de España por recuperar la hegemonía cultural en el mundo de habla hispana, que había perdido por la escasa influencia de la acción exterior española en los países latinoamericanos y que tendría que ver, por tanto, con una estrategia de naturaleza geopolítica (Cf. Trigo, 2012).

Durante años ha existido la idea de unos Estudios Transatlánticos que no eran sino la consecuencia de la añoranza colonial de España o de otras metrópolis, y su sentido se justificaba precisamente en la necesidad de elaborar un discurso que respondiera a esa inquietud. Nuestra 
propuesta difiere absolutamente de este planteamiento, y es ajena a toda apropiación o recreación neocolonial del concepto. Existe, a nuestro modo de entender, una necesidad académica y científica ineludible, que es la reconstrucción de las relaciones internacionales en un escenario de equilibrio y de solidaridad, capaz de hacer frente a la actual crisis económica y a los desequilibrios regionales, así como a los retos de la globalidad y de las nuevas tecnologías, y a los peligros que amenazan hoy día a la paz mundial. En este punto, la universidad puede cumplir un papel importante, alejándose de toda erudición para acercarse al mundo real, y ser proactiva y resolutiva. Cualidades que se relacionan directamente con la función de la universidad de transferencia de conocimiento a la sociedad. Hoy más que nunca es necesario repensar el espacio euroamericano, sin olvidar las relaciones que se derivan desde este eje hacia otros ámbitos geográficos. Pensemos en el caso español, cuya orientación se extiende además hacia el Mediterráneo y América Latina. O, como en otros casos, como Francia e Inglaterra, con cruces culturales que se desplazan también hacia África o Asia. Dando lugar así a un mosaico que alcanza a casi todo el mundo.

\section{Hacia la transdisciplinariedad}

¿Cuáles son, por tanto, los principales objetivos de nuestro enfoque? ¿Qué pretendemos con el desarrollo de este tipo de estudios? El camino trazado por la literatura comparada, y por el estudio de las influencias recíprocas en el plano literario y cultural puede servirnos de base, de camino ya explorado por quienes desde finales del siglo $x x$ han diseñado un nuevo espacio de la investigación. Sobre estos cimientos, los estudios transatlánticos comparados, desde una perspectiva pluridisciplinar, con el objetivo además de intentar ofrecer una visión holística de esta parte del mundo, pueden desarrollar una visión que permita complementar lo que la literatura ya ha puesto de relieve, y hacerse nuevas preguntas desde la diversidad disciplinar. Ése es nuestro enfoque, y el camino que queremos seguir, partiendo de las experiencias ya existentes, de las que somos deudores.

Nuestra posición de partida se halla en la necesidad de proponer un programa de estudios que permita a los egresados obtener una formación integral acerca de todo lo que concierne a las relaciones entre una y otra orilla del Atlántico. Evidentemente, prima en esta concepción previa una toma de posición en torno a la geopolítica como base de la formación de estos futuros expertos. Sin menoscabo de la especialización en cualquier otra rama del conocimiento, y en cualquier otra área geográfica del mundo, indudablemente todas ellas de particular interés, entendemos que la pertenencia a una misma área geoestratégica y a unas relaciones de proximidad mantenidas históricamente, pese a la existencia de un océano de por medio, siguen siendo importantes como categorías políticas (e inclusive, académicas) para el establecimiento de las relaciones internacionales.

La historia se ha encargado de poner de manifiesto los contactos que las naciones y pueblos que habitan a un lado y otro del Atlántico han establecido desde el siglo XV, y cómo estas relaciones humanas transoceánicas han ido creando un crisol de mixturas culturales y de mestizaje, y de influencias sociales, económicas, y políticas, salvando las grandes distancias geográficas. Desde este mismo punto de vista, el desplazamiento que se produce en estos momentos hacia otros puntos de interés de la escena internacional no nos debe hacer perder la perspectiva de que, ya sea visto desde Europa como desde América, nos encontramos en una zona del mundo que mantiene diferentes lazos políticos, económicos y culturales, con los pueblos y naciones de la otra orilla, muchos de ellos evidentemente consecuencia de un largo proceso colonizador e imperialista en el que han participado las metrópolis europeas, y posteriormente la potencia norteamericana.

Nuestra perspectiva es, asimismo, interdisciplinar y no etnocéntrica, porque trata de respetar la diversidad y huye de todo predominio académico y disciplinar. En este sentido, queremos que sea flexible, dialéctica, y democrática. Características que responden a un concepto de currículum abierto, como eslabón entre la sociedad exterior y la institución educativa (Cf. Gimeno: 1995). Cuando nos referimos a nuestra visión no etnocéntrica, queremos dejar de manifiesto que no partimos de una idea de reposicionamiento del hispanismo en el mundo, sino que nace con una voluntad de encuentro académico, que parta del análisis de las realidades nacionales y de las influencias recíprocas sin aspirar a ningún tipo de hegemonismo cultural. Nuestra perspectiva procede del enfoque histórico como premisa para entender la realidad del mundo de hoy. Somos conscientes de las dificultades que esto entraña, por la escasa tradición académica en otras áreas del conocimiento para abordar estudios comparados y complementarios, y también lo somos de la vaguedad del propio concepto de Estudios Transatlánticos, tal como ha explicado 
Sebastiaan Faber (2008). Para quien, "estos estudios cabe definirlos como un campo interdisciplinario que no presupone la unidad cultural del mundo hispánico sino que se concentra, dentro de un marco comparatista y transnacional, en las interacciones dinámicas y conflictivas que han venido caracterizando las relaciones entre España, Latinoamérica y Estados Unidos. Éstos, además, se conciben como tres espacios geográficos marcados más por su diversidad cultural y lingüística que por una supuesta identidad compartida, imputada a priori" (Faber, 2008: 316).

No debemos olvidar, sin embargo, el importante papel que el hispanismo puede desempeñar en el futuro en la arquitectura de nuestro propio proyecto, no en vano una amplia zona de este mundo que tratamos de estudiar habla en español. Pero los cruces y los mestizajes, y las aportaciones recíprocas, así como las diferentes políticas de ida y vuelta que se tejen en ese amplio mundo constituyen una parte fundamental del contenido que anima nuestra propuesta académica. El reto principal habrá de ser el de tratar de entender la complejidad de las relaciones sociales que tienen lugar en ese entorno geográfico. Como ha escrito Julio Ortega, "los estudios transatlánticos potencian distintas articulaciones disciplinarias y diferentes levantamientos del campo de estudios sociales y humanísticos (...). Parecen animadas por el principio, incluso la promesa, de vincular y ampliar estos espacios desdeel modelo concurrente del diálogo (lo que sabemos unos de otros) y de lo trans-disciplinario (lo que no sabemos uno del otro). (Ortega, 2006).

De acuerdo con este planteamiento, sobre todo en lo que concierne a su transdisciplinariedad, serán muy importantes los aportes procedentes de disciplinas y ciencias muy diversas, desde la literatura, que ha dado origen a los primeros Estudios Transatlánticos, pasando por la ciencia política, la comunicación, la economía, la sociología, la antropología, etc. Consideramos que nuestros futuros egresados deben tener una visión integral de este espacio geográfico y de sus cruces, con objeto de poder intervenir en él como especialistas, capaces de entender ese mundo y de analizar y diseñar políticas de intervención en diferentes ámbitos. Los estudios comparados ofrecen, en este sentido, una serie de ventajas académicas y científicas al plantear metodologías que implican la contextualización, la yuxtaposición y el análisis de las distintas realidades nacionales o regionales.

Probablemente, estemos, como ha puesto de relieve Julio Ortega, ante un campo cultural más que ante un área de estudio, pero no por ello debemos dejar de considerar la importancia que tiene el conocimiento de este campo, así como su amplitud y complejidad. La ampliación de los márgenes del conocimiento, desde las áreas de estudio a los campos culturales es una exigencia derivada de la necesidad de dar respuesta a problemas y cuestiones que trascienden el marco más reducido de las áreas específicas, que no siempre hallan la respuesta más adecuada a todas las preguntas. Cómo entender desde una perspectiva histórica y geopolítica todo el proceso de la globalización cultural si no nos planteamos nuevas interrogantes que no surgen ni de un área de conocimiento concreto ni de una geografía particular. Eso nos obliga, sin duda, a un acercamiento más complejo a los diferentes objetos de estudio, y exige una utilización plural de las teorías, de las metodologías, e incluso de las temáticas (Cf. Fernández de Alba, 2011). “Lo verdaderamente nuevo de los estudios transatlánticos - ha escrito Ortega - (es): su voluntad de no postular una sola teoría, ni una misma metodología, ni siquiera una agenda temática que privilegie unos núcleos de cotejo frente a otros. Por lo mismo, no fue propiamente un área de estudios sino un proyecto en construcción permanente, o sea, un campo cultural cuya asistematicidad es una red de espacios compartidos, secuencias y conjuntos" (Ortega, 2011). En cualquier caso, el conocimiento es un proceso siempre en construcción. Avanzaremos en él en la medida en que podamos articular redes de significación, que, una vez cruzadas y comparadas, nos permitirán mediante una relación dialéctica ir superando los límites impuestos por el conocimiento propio de un momento dado. Para qué, si no, partir del estado de la cuestión antes de abordar un problema de investigación, si no es porque entre el conocimiento existente y el que se está construyendo durante la investigación se ha de producir la confrontación necesaria para convertirlo en un proceso de construcción de nuevo conocimiento, que nos permita obtener las respuestas a nuestras nuevas interrogantes. En ese proceso de pregunta-respuesta-pregunta se van ampliando los límites del conocimiento.

\section{Los Estudios Transatlánticos y el mundo de hoy: a modo de epílogo}

Desde nuestro enfoque de Estudios Transatlánticos las nuevas interrogantes surgen de las preguntas de las distintas disciplinas ante los problemas comunes. La labor de coordinación
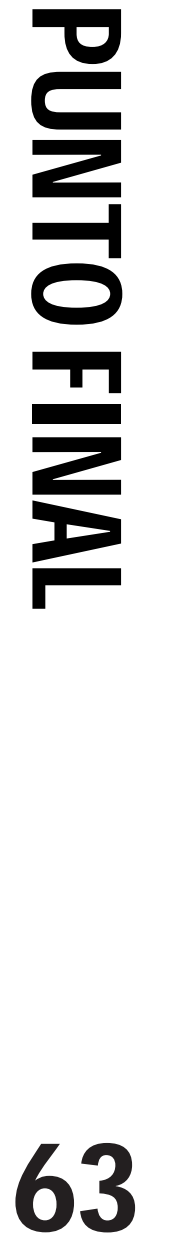


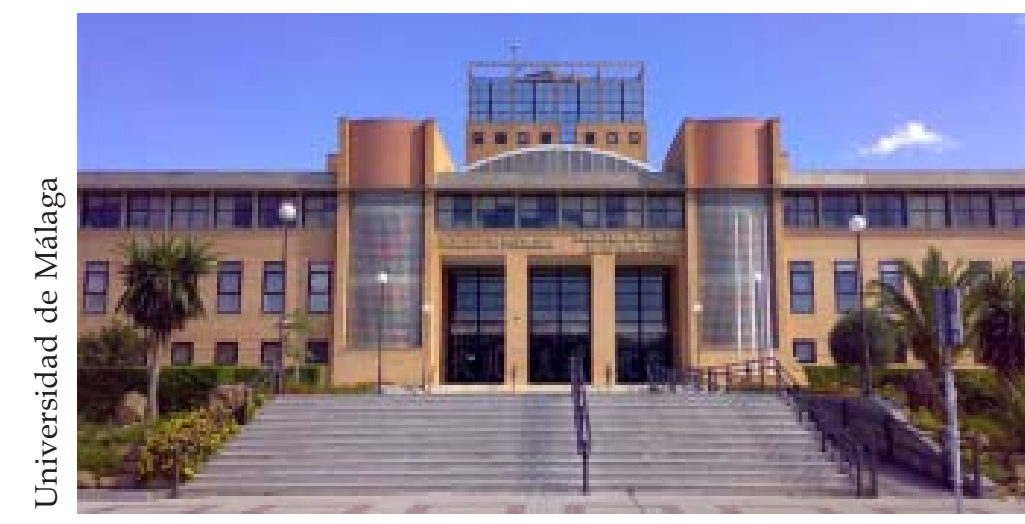

en este punto es esencial, y seguramente nada fácil, y es un reto para alcanzar nuestro objetivo de tratar de dar respuesta a problemas y situaciones de la vida real. Creemos en la cooperación y en la solidaridad como salida a las situaciones de conflicto y de riesgo. Los Estudios Transatlánticos deben fomentar por ello la cultura de la paz y de la convivencia, a partir de la defensa de modelos sociales y económicos más justos e igualitarios. Y en particular de la democracia como sistema político que, aun siendo perfectible, sigue siendo una aspiración difícil de alcanzar en muchos puntos del planeta. A pesar de las promesas de las grandes naciones para resolver los grandes problemas del mundo, sobre todo tras el final de la Segunda Guerra Mundial, lo cierto es que en la primera década del siglo XXI siguen dándose los mismos problemas, incluso de manera más acuciante: inestabilidad política internacional, crisis económica, grandes desequilibrios regionales, hambrunas, pobreza, analfabetismo, etc. Ni el desarrollo de las Nuevas Tecnologías ni la Globalización, que se presentaban como la panacea, han resuelto ninguno de esos problemas, al menos a gran escala. "No está claro -escribe Fontana - que la globalización haya favorecido la igualdad" (Fontana, 2012: 970). Del mismo modo que la igualdad, la libertad, la democracia, la calidad de vida, la distribución de la riqueza, la discriminación de la mujer, etc., ninguno de éstos, ni otros problemas, han encontrado la solución que se aventuraba en la segunda mitad del pasado siglo (Cf. Fontana, 2012). Es cierto que la historia es siempre irregular, y que las dinámicas de la economía y de la política sigue cursos en muchas ocasiones imprevisibles. Algunos de los países y regiones del eje Atlántico han sido protagonistas de los grandes acontecimientos del siglo XX, otros han sufrido esos mismos acontecimientos, o han permanecido invisibles para la historia oficial. La crisis actual del capitalismo está modificando el statu quo anterior, y frente al declive de las potencias tradicionales surgen nuevas economías emergentes. Un mundo en permanente cambio, que se plantea nuevas preguntas y que necesita nuevas respuestas.

Precisamente, aquí se encuentra también nuestro espacio académico y científico.

\section{Referencias bibliográficas}

- Faber, Sebastiaan. "Fantasmas hispanistas y otros retos transatlánticos", en: MORAÑA, Mabel (Ed.). Cultura y cambio social en América Latina. Madrid/Frankfurt: Iberoamericana/Vervuert, (2008).

- Fernández de Alba, Francisco. “Teorías de navegación: Métodos de los estudios transatlánticos”, en: Hispanófila, vol. 161, enero 2011, págs. 35-57.

- Fontana, Josep. Por el bien del Imperio. Historia del mundo desde 1945. Barcelona: Círculo de Lectores, (2012).

- Gimeno Sacristán, J. El currículum: una reflexión sobre la práctica. Madrid: Morata, (1995).

- Ortega, Julio. "Post-teoría y estudios transatlánticos", en: La ciudad literaria de Julio Ortega. http://blogs.brown.edu/ciudad_literaria/, (2006).

- Ortega, Julio. “Crítica

Transatlántica en el siglo XXI", en: La ciudad literaria de Julio Ortega. http:/ /

blogs.brown.edu/ ciudad_literaria/, (2011).

- Trigo, Abril, “Los estudios transatlánticos y la geopolítica del neohispanismo", en: Cuadernos de Literatura, No. 31, enerojunio de 2012, págs. 16-45.

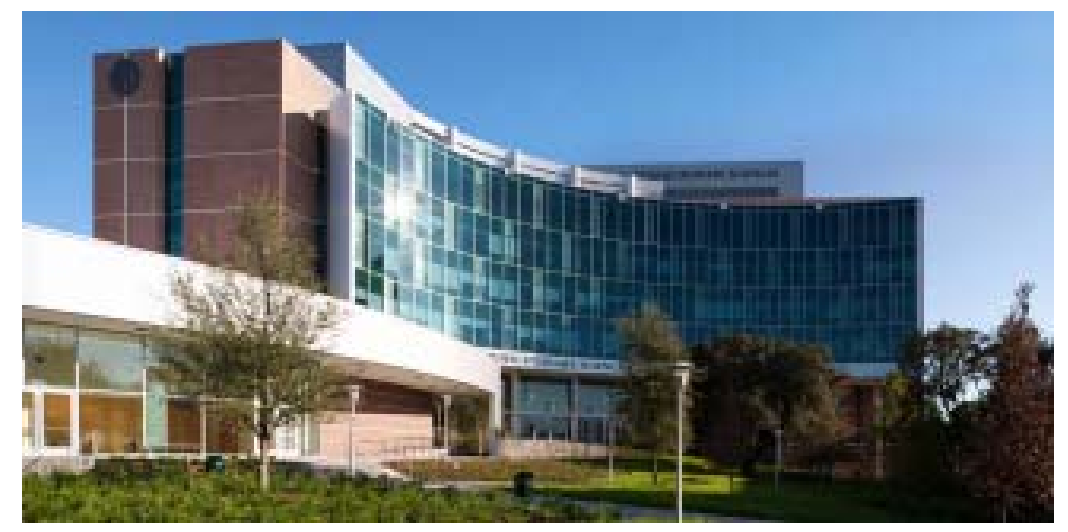

